\title{
IMPLANTAÇÃO DE UM MODELO DE ESTUDO PROSPECTIVO: UM ESTUDO DE CASO NO SEGMENTO DE PAINÉIS TIPO MDF, NO SETOR MADEIREIRO
}

\author{
Nicolle Christine Sotsek, Universidade Federal do Paraná, nicollesotsek@yahoo.com.br \\ Marcelo Gechele Cleto, Universidade Federal do Paraná, mgcleto@gmail.com
}

Introdução: No atual cenário, de progresso e expansão da indústria brasileira, a rotina das organizações sofre com as rápidas mudanças dos avanços tecnológicos, os quais vêm contribuindo para o aumento da competitividade. Desta forma, se faz necessário que as empresas preparem-se de maneira ordenada para enfrentar os novos desafios. A prospecção tecnológica é uma atividade capaz de orientar e conduzir o planejamento das atividades indústrias a longo prazo, pois visa entender as potencialidades, evolução, características e efeitos das mudanças tecnológicas. Neste contexto, elaborar projetos prospectivos é uma forma de contribuir para que a atividade do estudo de futuros se faça presente no meio industrial. Objetivos: Sendo assim, tem-se como objetivo da pesquisa analisar a aplicação de um modelo de estudo prospectivo, utilizando as metodologias Delphi e Cenários. Método: A pesquisa é aplicada, possuindo uma abordagem qualitativa, e se caracterizando como descritiva e exploratória em relação ao objetivo. O instrumento proposto para o trabalho é o estudo de caso. Este será realizado através de um grupo de especialistas nas áreas indústrias e na área de pesquisa. Resultados: Esperam-se como resultados, a validação do modelo de estudo prospectivo no setor madeireiro, e ainda, mostrar as principais vantagens e desvantagens da utilização dessas duas metodologias em associação.

Palavras-chave: Prospecção Tecnológica. Estudos de Futuros. Delphi. Cenários Prospectivos. 